\title{
Activation of the corticotropin-releasing factor receptor from the basolateral or central amygdala modulates nociception in guinea pigs
}

\author{
Alberto Ferreira Donatti ${ }^{1}$, Christie Ramos Andrade Leite-Panissi ${ }^{12^{*}}$ \\ ${ }^{1}$ Psychobiology Graduation Program, School of Philosophy, Science and Literature of Ribeirão Preto of the University of São Paulo, \\ Ribeirão Preto, Brazil \\ ${ }^{2}$ Department of Morphology, Physiology and Basic Pathology, Ribeirão Preto Dentistry School, University of São Paulo, Ribeirão \\ Preto, Brazil \\ Email: ${ }^{*}$ christie@,forp.usp.br
}

Received 25 April 2013; revised 27 May 2013; accepted 5 June 2013

Copyright (C) 2013 Alberto Ferreira Donatti, Christie Ramos Andrade Leite-Panissi. This is an open access article distributed under the Creative Commons Attribution License, which permits unrestricted use, distribution, and reproduction in any medium, provided the original work is properly cited.

\section{ABSTRACT}

Corticotropin-releasing factor (CRF) is a peptide that is released from the hypothalamus into widespread areas of the brain. Evidence has suggested that CRF is involved as a neuromodulator outside of the hypothalamic-pituitary-adrenal axis, playing an important role in fear, anxiety, depression and pain modulation. Our previous report demonstrated that CRF receptor activation in basolateral (BLA) or central nuclei of the amygdala $(\mathrm{CeA})$ produces innate fear in guinea pigs. Inhibition of these receptors via administration of $\alpha$-helical $\mathrm{CRF}_{9-41}$ (a nonspecific antagonist) into the CeA or BLA decreased innate fear behavior [1]. Additionally, there is strong evidence that emotional behavior and nociception can be modulated simultaneously. The present study was conducted to investigate the involvement of the CRF receptors of the BLA or $\mathrm{CeA}$ in nociception in guinea pigs. Guinea pigs were treated with CRF and $\alpha$-helical CRF9-41 in three different doses or injected with $\alpha$-helical $\mathrm{CRF}_{\text {9-41 }}$ preceded by CRF into the BLA or $\mathrm{CeA}$, and they were evaluated using the hot plate test. Our findings indicated that activation of $\mathrm{CRF}$ receptors in the BLA and in the CeA promoted antinociception, and this effect was reversed by preadministration of $\alpha$-helical $\mathrm{CRF}_{9-41}$ in the same area. The treatment with $\alpha$-helical $\mathrm{CRF}_{9-41}$ per se into the BLA and CeA did not alter nociception. Thus, nociception modulation occurs in a phasic manner, whereas defensive behavior can occur tonically because the $\alpha$-helical $\mathrm{CRF}_{\text {9-41 }}$ did not cause any modification on the index of analgesia in the hot plate test but did reduce innate

*Corresponding author. fear behavior [1].

Keywords: Amygdala; $\alpha$-Helical $\mathrm{CRF}_{9-41}$; Nociception; Acute Pain; Hot Plate Test

\section{INTRODUCTION}

Corticotropin-releasing factor (CRF) is a peptide comprising 41 amino acids that is synthesized and secreted in many regions of the brain and functions as a neurotransmitter and neuromodulator. This peptide is widely distributed within the brain, with its highest concentration in the hypothalamus and moderate to low levels in cortical and limbic structures [2]. There is extensive evidence that CRF functions as both a neurohormone and a neurotransmitter for coordinating endocrine, autonomic, and behavioral aspects of the stress response [3]. Additionally, note that analgesia is one of the characteristics of the stress reaction [4], and CRF has been recognized for its ability to produce analgesic effects $[5,6]$. In fact, previous reports have demonstrated that CRF receptors can modulate both emotional behavior and antinociception [7-9]. Thus, the activation of CRF receptors on mouse dorsal periaqueductal gray matter (dPAG) has produced anxiogenic and antinociceptive responses [8] that have been blocked by prior administration of a potent CRF type 1 receptor antagonist (NBI 27914) [8].

Furthermore, intracerebroventricular injections of CRF increase anxiety-like responses and stimulate pronounced increases in glutamate concentration in the central nu cleus of the amygdala, as measured using a microdialysis technique [9]. In contrast, intracerebroventricular administration of $\alpha$-helical CRF9-41 decreases the rat 
freezing response and increases the GABA concentration in the central nuclei of the amygdala (CeA). These results have suggested that the role of CRF in regulation of fear and anxiety is realized, at least in part, by modulating amino acid release in the amygdala [9].

In fact, the central nucleus of the amygdala (CeA) has one of the highest densities of CRF-immunoreactive neurons in the brain [10-12], but the basolateral nucleus of the amygdala (BLA) has the highest concentration of CRF receptors and a low density of CRF-immunoreactive perikarya [13]. An electrophysiological study has thus shown that the amygdala is an important site of CRF-mediated pain modulation [14]. Moreover, we previously reported that activation of CRF receptors in the BLA or the CeA produces a tonic immobility response in guinea pigs, a defensive behavior associated with innate fear and/or anxiety. In contrast, the inhibition of these receptors via the administration of $\alpha$-helical $\mathrm{CRF}_{9-41}$ into the CeA or BLA decreased the duration of the tonic immobility response [1]. These data suggest that the activation of the CRF receptors in the BLA or the CeA most likely produces fear and anxiety. Because there is activation of endogenous analgesic mechanisms responsible for the reduction of nociceptive responses during tonic immobility behavior [15], we designed the present study to investigate the effects of $\mathrm{CRF}$ receptor activation of the BLA and of the CeA on nociception. To this end, we investigated whether microinjection of CRF or of a CRF antagonist $\left(\alpha\right.$-helical $\left.\mathrm{CRF}_{9-41}\right)$ into the BLA or into the $\mathrm{CeA}$ in different groups of guinea pigs could alter the response in the hot plate test.

\section{MATERIALS AND METHODS}

\subsection{Animals}

Adult male guinea pigs (Cavia porcellus, from the University of São Paulo, Campus of Ribeirão Preto, Brazil) weighing 400-500 g $(\mathrm{n}=113)$ were kept in Plexiglas wall cages $(56 \times 17 \times 39 \mathrm{~cm}$, five guinea pigs per cage $)$ in a room maintained at $24^{\circ} \mathrm{C} \pm 1{ }^{\circ} \mathrm{C}$, on a $12 \mathrm{~h}$ light cycle, with free access to water and food throughout the experimental period. The experiments were carried out in compliance with the recommendations of $\mathrm{SBNeC}$ (the Brazilian Society of Neuroscience and Behavior) and with the approval of the Animal Care and Use Committee of the University of São Paulo-Brazil at the Ribeirão Preto campus (Protocol number 08.1.1368.53.1). All efforts were made to minimize animal suffering.

\subsection{Hot Plate Test}

The apparatus consists of an aluminum hot plate heated to $52^{\circ} \mathrm{C} \pm 0.5^{\circ} \mathrm{C}$ with a removable acrylic tub measuring $28 \mathrm{~cm}$ high, $26 \mathrm{~cm}$ long and $18 \mathrm{~cm}$ wide, in which the animals were placed. The dependent measure was the lag time(s) to licking the genitalia. Trials were terminated at 70 seconds to avoid tissue damage. The hot plate test was initially standardized for rats and mice, for which the dependent behavioral measure used as an index of nociception is licking a hind limb or jumping. However, guinea pigs do not exhibit these behaviors in this situation but rather lick their genitalia. Thus, we used the standardization of this test described by Leite-Panissi et al. [15]. After the guinea pigs recovered from surgery, we initially measured baseline latency in three consecutive trials at random time intervals. After this evaluation of baseline latency, the guinea pigs were subjected to microinjection of the study drug or a placebo in the CeA or the BLA. The animals were then subjected to six hot plate test trials, at 10-minute intervals over 60 minutes.

\subsection{Surgical Procedures}

Guinea pigs were anesthetized by an intramuscular injection of ketamine $(100 \mathrm{mg} / \mathrm{kg}$, St. Louis, MO) plus xylazine (14 mg/kg, Calier S.A., Barcelona, Spain) and placed in a stereotaxic apparatus (David-Kopf Instruments, USA) with the buccal piece $21.4 \mathrm{~mm}$ below the interauricular line. One guide cannula (14 $\mathrm{mm}$ in length and $0.6 \mathrm{~mm}$ in diameter, prepared from a hypodermic needle) was implanted into the left hemisphere toward the basolateral (BLA) or the central (CeA) nuclei of the amygdala. According to the Rössner atlas for guinea pig [16], the stereotaxic coordinates for the placement of the guide cannula implanted toward the BLA were $3.4 \mathrm{~mm}$ caudal to the bregma, $6.0 \mathrm{~mm}$ lateral to the midline, and $9.0 \mathrm{~mm}$ below the cortical surface. For the CeA, the coordinates were $3.4 \mathrm{~mm}$ caudal to the bregma, $6.1 \mathrm{~mm}$ lateral to the midline, and $7.5 \mathrm{~mm}$ below the cortical surface. The guide cannula was lowered to a depth of 1 $\mathrm{mm}$ above the target regions and fixed to the skull by means of a self polymerizing resin and an additional anchoring screw. At the end of surgery, each guide cannula was sealed with a stainless-steel wire to protect it from obstruction. In addition, the guinea pigs received a subcutaneous injection of the anti-inflammatory and analgesic Banamine (Schering-Plough, flunixin meglumine, 2.5 $\mathrm{mg} / \mathrm{kg}, 10 \mathrm{mg} / \mathrm{mL}, 0.2 \mathrm{~mL}$ ). Afterwards, the guinea pigs were given a period of one week to recover from the surgical procedure.

\subsection{Experimental Groups}

As noted above, after recovering from surgery, the animals were subjected to baseline latency measurement on three consecutive hot plate test trials at random time intervals without administering a drug or placebo. The animals were then divided into different experimental groups for each brain area (BLA and CeA) to evaluate 
the effects of the drugs. Group 1 guinea pigs ( $\mathrm{n}=7 \mathrm{BLA}$; $\mathrm{n}=8 \mathrm{CeA}$ ) received $0.9 \%$ saline, group 2 guinea pigs were microinjected with CRF (an agonist of CRF recaptors) with $0.2 \mu \mathrm{g}(\mathrm{n}=8 \mathrm{BLA} ; \mathrm{n}=7 \mathrm{CeA}), 0.5 \mu \mathrm{g}(\mathrm{n}=6$ $\mathrm{BLA} ; \mathrm{n}=7 \mathrm{CeA})$, or $1.0 \mu \mathrm{g}(\mathrm{n}=6 \mathrm{BLA} ; \mathrm{n}=7 \mathrm{CeA})$ doses. To evaluate the effect of blocking CRF receptors, Group 3 was treated with $\alpha$-helical CRF9-41 (an antagonist of CRF receptors) with $0.2 \mu \mathrm{g}(\mathrm{n}=9$ BLA; $\mathrm{n}=7$ $\mathrm{CeA}), 0.5 \mu \mathrm{g}(\mathrm{n}=7$ BLA; $\mathrm{n}=7$ CeA), or $1.0 \mu \mathrm{g}(\mathrm{n}=6$ BLA; $n=7 \mathrm{CeA}$ ) doses. Finally, to analyze blocking of the CRF receptor before CRF administration, Group 4 guinea pigs were microinjected with $\alpha$-helical CRF9-41 $(0.2 \mu \mathrm{g})$, and after five minutes, an effective dose of CRF $(1.0 \mu \mathrm{g})$ was administered into the BLA or CeA $(\mathrm{n}=7$ to BLA or $\mathrm{n}=7$ to CeA). All of the drugs were administered with a volume of $0.2 \mu$.

\subsection{Drugs and Microinjection Procedure}

Corticotrophin releasing factor (a nonselective CRF receptor agonist) and $\alpha$-helical $\mathrm{CRF}_{9-41}$ (a nonselective CRF receptor antagonist) were obtained from Sigma (St. Louis, MO). The solutions were freshly dissolved in $0.9 \%$ sterile saline. The doses used were based on a previous study [17]. The microinjections were performed on awake animals using a Hamilton microsyringe $(10 \mu \mathrm{l})$ connected to a PE-10 polyethylene catheter that was coupled to a thin dental needle $(0.3 \mathrm{~mm}$ O.D; $0.1 \mathrm{~mm}$ longer than the guide cannula). A volume of $0.2 \mu \mathrm{l}$ was microinjected over a period of $1 \mathrm{~min}$, and the needle was left in place for an additional $40 \mathrm{~s}$ to avoid reflux.

\subsection{Histological Verification}

At the end of the experiments, the guinea pigs were given a lethal dose of chloral hydrate $(500 \mathrm{mg} / \mathrm{kg}$, i.p.) and perfused intracardially with saline followed by $10 \%$ formalin. The brains were removed and fixed in $10 \%$ formalin. The tissue was submitted for routine histologycal processing, and sections were observed under a microscope to determine the locations of the stimulated sites using the Rössner atlas [16]. Only the guinea pigs with microinjections that reached the target structure were used for data analysis.

\subsection{Statistical Analysis}

Data from the hot plate test were normalized using an index of analgesia (IA) according to the following formula: hot plate test - hot plate control/cut off time- - hot plate control, where hot plate control is the average of 3 baseline measurements of hot plate latencies, and hot plate test is the latency recorded for each animal during experimental trials. The data are reported as the means \pm SEM and were analyzed by repeated measures multivari- ate analysis of variance (ANOVA) using time as a within-subject factor and treatment (control, $\alpha$-helical $\mathrm{CRF}_{9-41}$ and CRF) as between-subject factors. Tukey's post hoc test was used to determine the difference between treatments, with the level of significance set at $\mathrm{P}<$ 0.05 .

\section{RESULTS}

The results indicate that the activation of CRF receptors in the BLA and CEA by microinjection of CRF at a concentration of $1.0 \mu \mathrm{g}$ promoted an increase in the index of analgesia (IA, Figures 1 and 2). Additionally, the pretreatment with $\alpha$-helical $\mathrm{CRF}_{9-41}$ in the BLA or CEA blocked the effect of CRF in the same areas (Figures 1(a) and 2(a)). Moreover, the administration of the antagonist for $\mathrm{CRF}$ receptors, $\alpha$-helical $\mathrm{CRF}_{9-41}$ in the $\mathrm{CeA}$ and BLA, did not alter the IA in the hot plate test (Figures 1(b) and 2(b)).

Two-way ANOVA applied for the different groups that received microinjections into BLA showed a difference with respect to time $\left(\mathrm{F}_{6,776}=0.74, \mathrm{P}<0.05\right)$, with respect to treatment $\left(\mathrm{F}_{7,776}=34.67, \mathrm{P}<0.05\right.$, two-way ANOVA $)$ and an interaction between time and treatment $\left(\mathrm{F}_{42,776}=\right.$ $1.18, \mathrm{P}<0.05$, two-way ANOVA). The post-hoc Newman-Keuls test showed a significant difference in the IA between group CRF $1.0 \mu \mathrm{g}$ at intervals of 10 to $60 \mathrm{~min}$ utes compared to the other groups over time (Figure 1(a)). In addition, the IA of the other groups did not differ during all other experimental conditions (Figures 1(a) and (b)).

In regard to the groups that received different dosages in the CeA, the two-way ANOVA showed differences in time $\left(\mathrm{F}_{6,835}=4.59, \mathrm{P}<0.05\right)$, in treatment $\left(\mathrm{F}_{7,835}=30.65\right.$, $\mathrm{P}<0.05)$ and an interaction between time and treatment $\left(F_{42,835}=1.53, \mathrm{P}<0.05\right)$. The post-hoc Newman-Keuls test showed a significant difference in the IA between the $\mathrm{CRF}$ in the $1.0 \mu \mathrm{g}$ group at the intervals of 10 to $50 \mathrm{~min}-$ utes compared to the other groups over time (Figure 2(a)). Moreover, the IA of the other groups did not differ during all other experimental conditions (Figures 2(a) and (b)).

Figure 3 illustrates the sites where the microinjections were administered in the basolateral or central nuclei of the amygdala for all experimental groups.

\section{DISCUSSION}

This study shows that the activation of CRF receptors of the basolateral and central nuclei of the amygdala increased the index of analgesia (IA) in the hot plate test. This antinociceptive effect, induced by the microinjection of CRF $1.0 \mu \mathrm{g}$, was blocked by pretreatment with the CRF receptor antagonist $\alpha$-helical $\mathrm{CRF}_{9-41}$ in the same area. However, the $\alpha$-helical $\mathrm{CRF}_{9-41}$ per se did not 


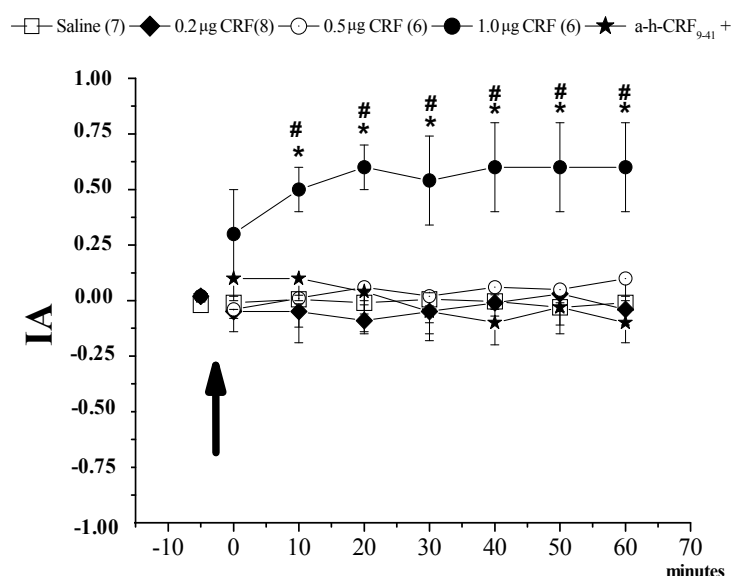

(a)

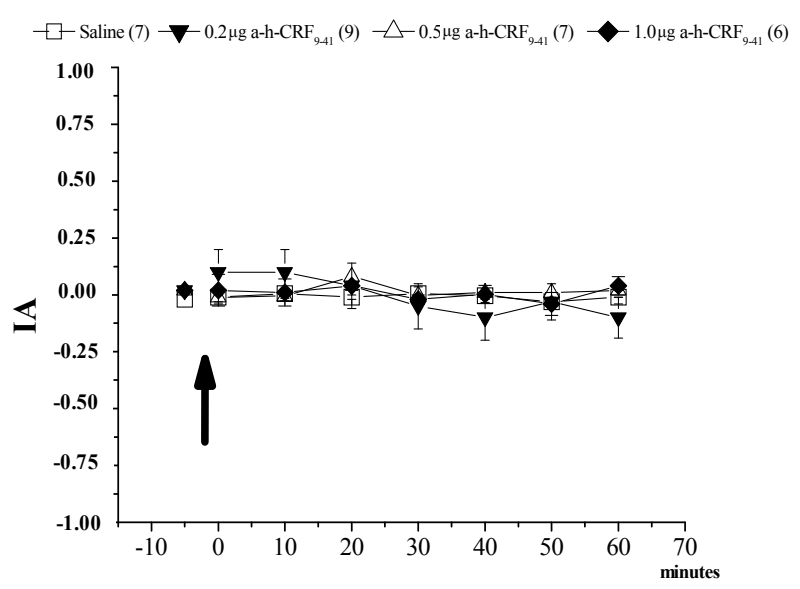

(b)

Figure 1. Modulation of nociception in the hot plate test (IA: index of analgesia) by the corticotropin-releasing factor (CRF) in the basolateral nucleus of the amygdala (BLA). (a): Means \pm SEM. IA in the control group (Saline) and after microinjection of corticotropin-releasing factor (CRF) at $0.5 \mu \mathrm{g}, 0.2 \mu \mathrm{g}$ and $1.0 \mu \mathrm{g}$ doses for three different groups into the basolateral amygdala, and after the treatment with the CRF antagonist $\left(\alpha-\right.$ h-CRF $_{9-41}$ at the dose $0.2 \mu \mathrm{g}$ ) plus CRF $1.0 \mu \mathrm{g}$. (b): Means \pm SEM. IA in the control group (Saline) and after microinjection of an antagonist of corticotropin-releasing factor ( $\alpha$-h-CRF 9-41) at $0.5 \mu \mathrm{g}, 0.2 \mu \mathrm{g}$ and $1.0 \mu \mathrm{g}$ doses for three different groups into the basolateral amygdala. ${ }^{*} \mathrm{P}<0.05$ compared to Saline and ${ }^{\#} \mathrm{P}<0.05$ compared to $\alpha$-h-CRF group by the Newman-Keuls test. The number in parentheses represents the number of animals in each group.

alter the IA. Note that the inhibition of these receptors via the administration of $\alpha$-helical $\mathrm{CRF}_{9-41}$ in the BLA or CeA reduced innate fear and/or anxiety [1]. Thus, it is possible to hypothesize that the CRF receptors of the BLA and $\mathrm{CeA}$ are involved in a nociceptive regulation mechanism, but they do not share this tonic circuitry.

There is strong evidence that CRF has antinociceptive properties in animal models, both centrally and peripherally [18]. Furthermore, antinociception has been shown

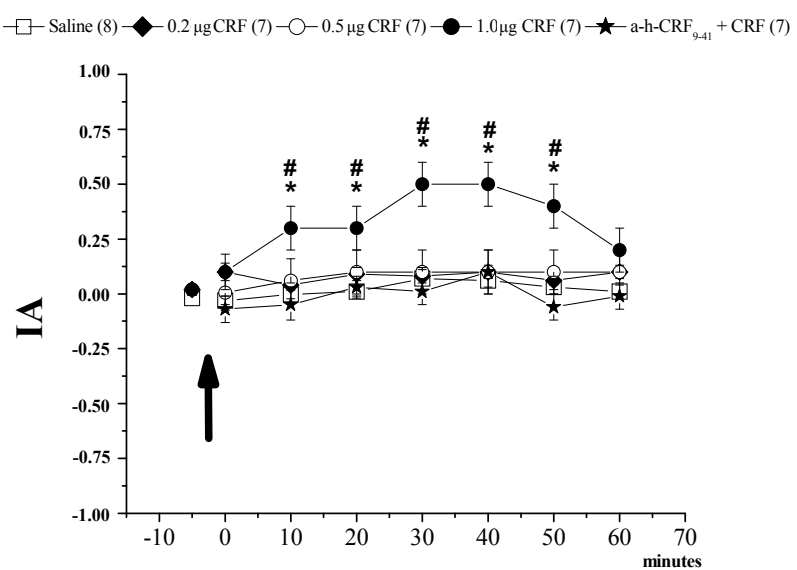

(a)

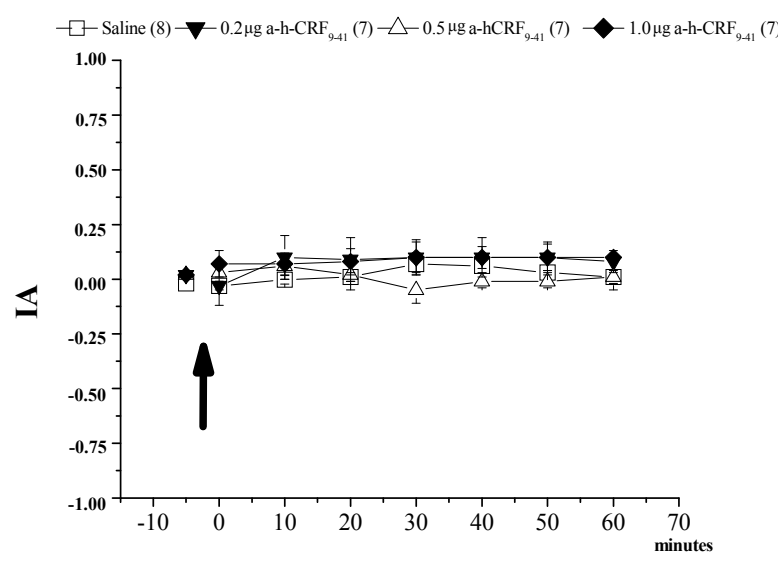

(b)

Figure 2. Modulation of nociception in the hot plate test (IA: index of analgesia) by the corticotropin-releasing factor (CRF) in the central nucleus of the amygdala (CeA). (a): Means \pm SEM. IA in the control group (Saline) and after microinjection of corticotropin-releasing factor (CRF) at $0.5 \mu \mathrm{g}, 0.2 \mu \mathrm{g}$ and $1.0 \mu \mathrm{g}$ doses for three different groups into the basolateral amygdala, and after the treatment with the CRF antagonist $\left(\alpha-\right.$ h-CRF $_{9-41}$ at the dose $\left.0.2 \mu \mathrm{g}\right)$ plus CRF $1.0 \mu \mathrm{g}$. (b): Means \pm SEM. IA in the control group (Saline) and after microinjec- tion of an antagonist of corticotropin-releasing factor $\left(\alpha-h-C F_{9-41}\right)$ at $0.5 \mu \mathrm{g}, 0.2 \mu \mathrm{g}$ and $1.0 \mu \mathrm{g}$ doses for three different groups into the basolateral amygdala. ${ }^{*} \mathrm{P}<0.05$ compared to Saline and ${ }^{\#} \mathrm{P}<0.05$ compared to $\alpha-\mathrm{h}-\mathrm{CRF}_{9-41}$ group by the NewmanKeuls test. The number in parentheses represents the number of animals in each group.

to be induced by different routes of administration, including intracerebroventricular, intrathecal, and intracisternal [19-21]. However, the mechanisms by which this peptide acts are still unclear [22]. Previous studies have suggested that the analgesic effect of CRF on somatic pain sensitivity may be mediated by both opioid and non-opioid mechanisms $[23,24]$. For example, a previous report [25] demonstrated that CRF administered i.c.v in anesthetized rats has an analgesic effect on sensitivity to somatic pain (caused by electrical current). This effect 


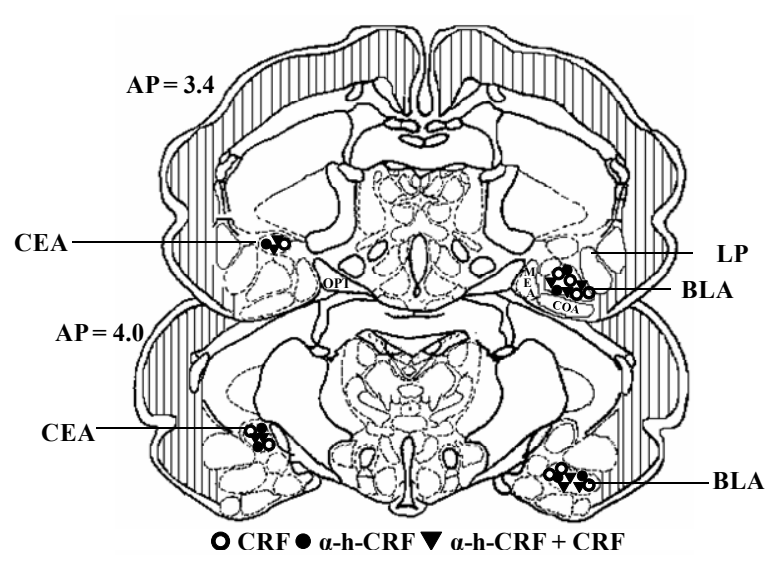

(a)

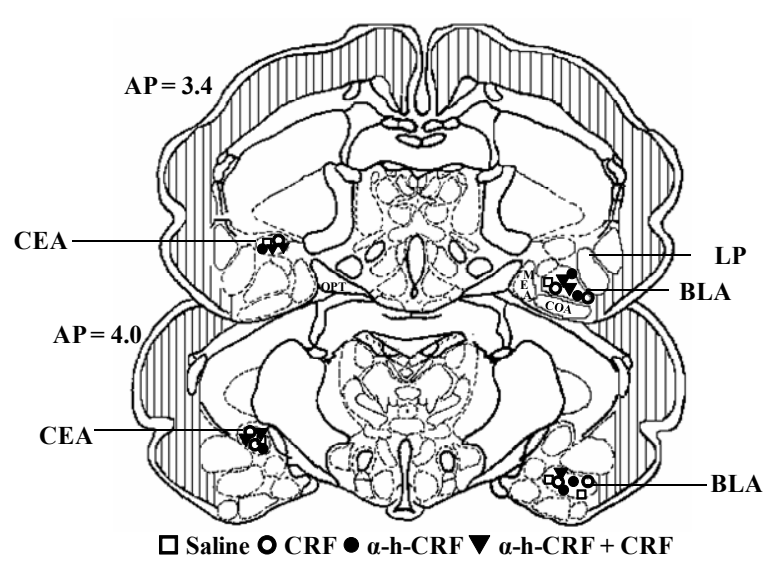

(b)

Figure 3. Schematic drawing of the frontal sections obtained at representative levels of the guinea pig amygdala. (a) Representation of the microinjection sites in the basolateral (BLA) and central (CeA) nuclei of the amygdala. The open square $(\square)$ represent the sites where Saline was microinjected. The open circles (O) represent the sites where corticotropin-releasing factor $(\mathrm{CRF})$ was microinjected. The filled circles $(\bullet)$ represent the sites where alpha-helical-CRF ${ }_{9-41}(\alpha-h-C R F)$ was microinjected. The filled triangles $(\boldsymbol{\nabla})$ represent the sites where CRF preceded by $\alpha$-h-CRF was microinjected. All microinjections were made on the left side, but some groups are illustrated on the right for clarity. (b) Representative photomicrographs of microinjection into the basolateral (BLA, left panel) or into the central nuclei of the amygdala (CEA, right panel). The number of points in the figures is less than the total number of guinea pigs $(n=112)$ due to several overlaps. Abbreviations: BLA: basolateral amygdala; CEA: central amygdala; LP: lateral amygdala; MEA: medial amygdala; OPT: optic tract.

must have been mediated by a non-opioid mechanism associated with endogenous glucocorticoid receptors because the effect was abolished by a glucocorticoid receptor antagonist (RU 38486). In contrast, blockage of the opioid system by naltrexone, but not by a glucocorticoid receptor antagonist (RU 38486), eliminated the analgesic effect of CRF in conscious rats exposed to a thermal stimulus, revealing an opioid-associated mecha- nism [26].

With regard to the central action of CRF, studies have shown that the release of this peptide can modulate a variety of behavioral [24], autonomic [27], endocrine [28] and nociceptive responses [29]. CRF exerts these effects by acting as a neurotransmitter and/or neuromodulator in many structures of the central nervous system (CNS), especially in extrahypothalamic centers [30] such as the locus coeruleus [31], hippocampus [32] and amygdala $[6,14]$.

Whereas CRF is primarily related to responses associated with stress, Bardin et al. [33] suggest that the dual modulation of CRF in the nociceptive system can be directly related to the anti- and pro-nociceptive effects observed in emotional situations [34-36]. The antinociceptive action of acute stress is widely known in animals and humans [36]. Moreover, it has been reported that continuous stress results in hyperalgesia or allodynia $[34,35]$. Exposure to chronic stress in humans increases pain sensitivity and reduces the pain threshold [35], which can be explained by the elevation of corticosterone in the amygdala. It is possible that the increased release of corticosterone to promote long-term changes in neurotransmission in the amygdala results in increased anxiety and visceral hypersensitivity and decreased somatic pain sensitivity $[37,38]$.

The central (CeA) and basolateral nuclei (BLA) of the amygdala play an important role in regulating fear, anxiety, and affective responses $[1,39,40]$ and in the modulation of nociception [41,42]. Previous electrophysiologycal [6], biochemical [43-45] and behavioral findings $[18,27]$ have suggested that amygdaloid CRF receptors are involved in nociceptive modulation. The microinjection of a nonselective antagonist of CRF receptors in the amygdala reversed the hyperalgesia induced by opioid withdrawal as evaluated by the tail flick test in rats [27]. Nonetheless, Ji and Neugebauer [14] showed that intraamygdaloid administration of the $\mathrm{CRF}_{1}$ receptor antagonist, but not the $\mathrm{CRF}_{2}$ antagonist, inhibits central sensitization of neurons in a model of inflammation nociception. Note that in the present study, the administration of the CRF antagonist per se did not alter the IA in the hot plate test in guinea pigs. Thus, it is possible to suggest that CRF receptors can differentially modulate an acute thermal nociceptive stimulus (hot plate test) and nociception associated with a persistent condition (hyperalgesia and inflammation).

Another previous study has shown that high concentrations of CRF $(10 \mathrm{mM})$ administered into the central nucleus of amygdala promoted an antinociceptive effect in rats, and a $\mathrm{CRF}_{2}$ receptor antagonist reversed this antinociception. In contrast, treatment with low concentrations of CRF ( $0.01 \mathrm{mM}$ to $1 \mathrm{mM}$ ) in the central nucleus of amygdala facilitated nociception that was 
blocked by pretreatment with a $\mathrm{CRF}_{1}$ receptor antagonist [6]. Different studies have suggested that $\mathrm{CRF}_{1}$ receptors mediate pro-nociceptive effects of $\mathrm{CRF}$, whereas $\mathrm{CRF}_{2}$ receptors have an antinociceptive effect [46-51].

With regard to the CRF mechanisms involved in the modulation of defensive behavior and the antinociceptive response, the activation of CRF receptors in dorsal periaqueductal gray matter (dPAG) has produced anxiogenic and antinociceptive responses in mice that have in turn been blocked by prior administration of a potent CRF type 1 receptor (NBI 27914) [8]. These results corroborate the present study, where the administration of $\mathrm{CRF}$ in the BLA and CeA promoted an antinociceptive effect that was reversed by the pre-administration of a CRF receptor antagonist $\left(\alpha\right.$-helical $\left.\mathrm{CRF}_{9-21}\right)$ in the same areas. Our previous report also demonstrated that the activation of CRF receptors in the BLA or CeA potentiates a tonic immobility response (a defensive behavior associated with innate fear and/or anxiety) in guinea pigs [1]. However, the inhibition of these receptors via $\alpha$-helical $\mathrm{CRF}_{9-41}$ administration into the CeA or BLA decreased the duration of the tonic immobility response [1], but it did not alter the IA in the hot plate test in the present study. These results taken together show that amygdaloid CRF receptors modulate emotional behavior and nociception but do not share the same circuitry.

In summary, the present results show that the CRF receptors in the BLA and CeA modulate nociception and that these same receptors can be involved in the modulation of fear and anxiety [1]. Moreover, the thermal nociception modulation occurs in a phasic manner, whereas the defensive behavior can occur tonically because the administration of a non-specific antagonist for CRF receptors $\alpha$-helical $\mathrm{CRF}_{9-41}$ did not cause any modification on the IA in the hot plate test, but it did reduce innate fear behavior [1].

\section{ACKNOWLEDGEMENTS}

The authors would like to thank Patrícia Adriana Basile for her technical assistance. This work was supported by CAPES/PROEX, FAPESP (2010/10936-5). A.F. Donatti has a doctorate scholarship from CAPES and C.R.A. Leite-Panissi also received grants from the CNPq (Grant No. 307383/2012-1).

\section{REFERENCES}

[1] Donatti, A.F. and Leite-Panissi, C.R.A. (2011) Activation of corticotropin-releasing factor receptors from the basolateral or central amygdala increases the tonic immobility response in guinea pigs: An innate fear behavior. Behavioural Brain Research, 225, 23-30. doi:10.1016/j.bbr.2011.06.027

[2] Bittencourt, J.C. and Sawchenko, P.E. (2000) Do centrally administered neuropeptides access cognate recap- tors? An analysis in the central corticotrophin-releasing factor system. Journal Neuroscience, 20, 1142-1156.

[3] Owens, M.J. and Nemeroff, C.B. (1991) Physiology and pharmacology of corticotropin-releasing factor. Pharmacology Review, 43, 425-73.

[4] Butler R.K. and Finn D.P. (2009) Stress-induced analgesia. Progress in Neurobiology, 88, 184-202. doi:10.1016/j.pneurobio.2009.04.003

[5] Vit, J.P., Clauw, D.J., Moallem, T., Boudah, A., Ohara, P.T. and Jasmin, L. (2006) Analgesia and hyperalgesia from CRF receptor modulation in the central nervous system of Fischer and Lewis rats. Pain, 121, 241-260. doi:10.1016/j.pain.2005.12.024

[6] Ji, G. and Neugebauer, V. (2008) Pro-and anti-nociceptive effects of corticotropin-releasing factor (CRF) in central amygdala neurons are mediated through different receptors. Journal of Neurophysiology, 99, 1201-1212. doi:10.1152/jn.01148.2007

[7] Miguel, T.T., Gomes, K.S. and Nunes-De-Souza, R.L. (2012) Contrasting effects of nitric oxide and corticotropin-releasing factor within the dorsal periaqueductal gray on defensive behavior and nociception in mice. Brazilian Journal of Medical and Biological Research, 45, 299-307. doi:10.1590/S0100-879X2012007500043

[8] Miguel, T.T. and Nunes-De-Souza, R. L. (2011) Anxiogenic and antinociceptive effects induced by corticotropin-releasing factor (CRF) injections into the periaqueductal gray are modulated by CRF1 receptor in mice. Hormone Behavioral, 60, 262-300. doi:10.1016/j.yhbeh.2011.06.004

[9] Skorzewska, A., Bidzinski, A., Hamed, A., Lehner, M. and Turzynska, D., Sobolewska, A., et al. (2009) The effect of CRF and alpha-helical $\mathrm{CRF}_{9-41}$ on rat fear responses and amino acids release in the central nucleus of the amygdala. Neuropharmacology, 57, 148-156. doi:10.1016/j.neuropharm.2009.04.016

[10] Cummings, S., Elde, R., Ells, J. and Lindall A. (1983) Corticotropin releasing factor immunoreactivity is widely distributed within the central nervous system of the rat: An immunohistochemical study. Journal Neuroscience, 3, 1355-1368.

[11] Palkovits, M., Brownstein, M. J. and Vale, W. (1985) Distribution of corticotropin releasing factor in the rat brain. FASEB Journal, 44, 215-219.

[12] Swanson, L.W., Sawchenko, P.E., Rivier, J. and Vale, W.W. (1983) Organization of ovine corticotropin-releasing factor immunoreactive cells and fibers in the rat brain: An immunohistochemical study. Neuroendocrinology, 36,165-186. doi:10.1159/000123454

[13] De Souza, E.B., Insel, T.R., Perrin, M.H., Rivier, J., Vale, W. and Kuhar, M.J. (1985) Corticotropin releasing factor receptors are widely distributed within the rat central nervous system: An autoradiographic study. Journal Neuroscience, 5, 3189-3203.

[14] Ji, G. and Neugebauer, V. (2007) Differential effects of CRF1 and CRF2 receptor antagonists on pain-related sensitization of neurons in the central nucleus of the 
amygdala. Journal Neurophysiology, 97, 3893-3904. doi:10.1152/jn.00135.2007

[15] Leite-Panissi, C.R.A., Rodrigues, C.L., Brentegani, M.R. and Menescal-De-Oliveira, L. (2001) Endogenous opiate analgesia induced by tonic immobility in guinea pigs. Brazilian Journal Medical and Biological Research, 34, 245 - 250. doi:10.1590/S0100-879X2001000200013

[16] Rössner, W. (1965) Steretaktischer hirnatlas von meerchwlinchen. Palla Velag, Munich.

[17] Cui, X.Y., Lundeberg, T. and Yu, L.C. (2004) Role of corticotrophin-release factor and its receptor in nociceptive modulation in the central nucleus of amygdale in rats. Brain Research, 995, 23-28. doi:10.1016/j.brainres.2003.09.050

[18] Lariviere, W. R. and Melzack, R. (2000) The role of corticotropin-releasing factor in pain and analgesia. Pain, 84, 1-12. doi:10.1016/S0304-3959(99)00193-1

[19] Hargreaves K.M., Flores, C.M., Dionne, R.A., Mueller, G.P. (1990) The role of pituitary beta-endorphin in mediating corticotropin-releasing factor-induced antinociception. American Journal Physiology, 258, E235-242.

[20] Song, Z. H. and Takemori, A. (1990) E. Involvement of spinal kappa opioid receptors in the antinociception produced by intrathecally administered corticotropin-releasing factor in mice. Journal of Pharmacology and Experimental Therapy, 254, 363-368.

[21] Bianchi, M. and Panerai, A.E. (1995) CRH and the noradrenergic system mediate the antinociceptive effect of central interleukin- $1 \alpha$ in the rat. Brain Research Bulletin, 36, 113-117. doi:10.1016/0361-9230(94)00174-Y

[22] Lautenbacher, S., Roscher, S., Kohl, G., Vedder, H. and Krieg, J. (1999) Corticotropin-releasing-hormone lacks analgesic properties: An experimental study in humans, using non-inflammatory pain. Pain, 83, 1-7. doi:10.1016/S0304-3959(99)00072-X

[23] Sawamura, S., Obara, M., Taked, A.K., Maze, M. and Hanaoka, K. (2003) Corticotropin-releasing factor mediates the antinociceptive action of nitrous oxide in rats. Anesthesiology, 99,708-715. doi:10.1097/00000542-200309000-00028

[24] Yarushkina, N.I. (2008) The role of hypothalamo-hypophyseal-adrenocortical system hormones in controlling pain sensitivity. Neuroscience Behavioral and Physiology, 38,759-766. doi:10.1007/s11055-008-9044-Z

[25] Yarushkina, N.I., Bagaeva, T.R. and Filaretova, L.P. (2011) Central corticotropin-releasing factor (CRF) may attenuate somatic pain sensitivity through involvement of glucocorticoids. Journal of Physiology and Pharmacology, 62,541-548.

[26] Yarushkina, N.I. and Bagaeva, T.R. (2011) Mechanism of the analgesic effect of corticotropin-releasing factor in conscious rats. Neuroscience Behavioral Physiology, 41, 500-505. doi:10.1007/s11055-011-9444-3

[27] McNally, G.P. and Akil, H. (2002) Role of corticotropin-releasing hormone in the amygdala and bed nucleus of the stria terminalis in the behavior, pain modulatory, and endocrine consequences of opiate withdrawal. $\mathrm{Neu}$ roscience, 112, 605-617.

\section{doi:10.1016/S0306-4522(02)00105-7}

[28] Steckler, T. (2001) The molecular neurobiology of stress -Evidence from genetic and epigenetic models. Behavioural Pharmacology, 12,381-427. doi:10.1097/00008877-200111000-00002

[29] Rouwette, T., Klemann, K., Gaszner, B., Scheffer, G.J., Roubos, E.W., Scheenen, W.J., Vissers, K. and Kozicz, T. (2011) Differential responses of corticotropin-releasing factor and urocortin 1 to acute pain stress in the rat brain. Neuroscience, 183, 15-24.

doi:10.1016/j.neuroscience.2011.03.054

[30] Deyama, S., Nakagawa, T., Kaneko, S., Uehara, T. and Minami, M. (2007) Involvement of the bed nucleus of the stria terminalis in the negative affective component of visceral and somatic pain in rats. Behavioural Brain Research, 176, 367-371. doi:10.1016/j.bbr.2006.10.021

[31] Valentino, R.J. and Foote, S.L. (1987) Corticotropinreleasing factor disrupts sensory responses of brain noradrenergic neurons. Neuroendocrinology, 45, 28-36. doi: $10.1159 / 000124700$

[32] Aldenhoff, J.B., Gruol, D.L., Rivier, J., Vale, W. and Siggins, G.R. (1983) Corticotropin releasing factor decreases postburst hyperpolarizations and excites hippocampal neurons. Science, 221, 875-877.

doi:10.1126/science. 6603658

[33] Bardin, L., Malfetes, N., Newman-Tancredi, A. and Depoortere, R. (2009) Chronic restraint stress induces mechanical and cold allodynia, and enhances inflammatory pain in rat: Relevance to human stress-associated painful pathologies. Behavioural Brain Research, 205, 360-366. doi:10.1016/j.bbr.2009.07.005

[34] Gamaro, G.D., Xavier, M.H., Pilger, J.A., Ely, D.R. and Dalmaz, C. (1998) The effect acute and repeated restraint stress on the nociceptive response in rats. Physiology and Behavior, 63, 693-697. doi:10.1016/S0031-9384(97)00520-9

[35] Caceres, C. and Burns, J.W. (1997) Cardiovascular reactivity to psychological stress may enhance subsequent pain sensitivity. Pain, 69, 237-244. doi:10.1016/S0304-3959(96)03289-7

[36] Amit, Z. and Galina, Z.H. (1986) Stress-induced analgesia: Adaptative pain suppression. Physiological Review, 66, 1091-120.

[37] Myers, B., Dittmeyer, K. and Greenwood-Van Meerveld, B. (2007) Involvement of amygdaloid corticosterone in altered visceral and somatic sensation. Behavioural Brain Research, 181, 163-167. doi:10.1016/j.bbr.2007.03.031

[38] Myers, B. and Greenwood-Van Meerveld B. (2007) Corticosteroid receptor-mediated mechanisms in the amygdala regulate anxiety and colonic sensitivity. American Journal Physiology Gastrointestinal and Liver Physiology, 292, 1622-1629. doi:10.1152/ajpgi.00080.2007

[39] Shekhar, A., Truit, W., Rainnie, D. and Sajdyk, T. (2005) Role of stress, corticotrophin releasing factor (CRF) and amygdale plasticity in chronic anxiety. Stress, 8, 209-219. doi:10.1080/10253890500504557

[40] Phelps, E.A. and LeDoux, J.E. (2005) Contributions of the amygdala to emotion processing: from animal models 
to human behaviour. Neuron, $\mathbf{4 8}, 175-187$. doi:10.1016/j.neuron.2005.09.025

[41] Xu, W., Lundeberg, T., Wang, Y.T., Li, Y. and Yu, L.C. (2003) Antinociceptive effect of calcitonin gene-related peptide in the central nucleus of amygdala: Activating opioid receptors through amygdala-periaqueductal gray pathway. Neuroscience, 118, 1015-1022. doi:10.1016/S0306-4522(03)00069-1

[42] Leite-Panissi, C.R.A., Brentegani, M.R. and Menescalde-Oliveira, L. (2004) Cholinergic-opioidergic interaction in the central amygdala induces antinociception in the guinea pig. Brazilian Journal and Medical Biology Research, 37, 1571-1579. doi:10.1590/S0100-879X2004001000018

[43] Greenwood-Van Meerveld, B., Johnson, A. C., Schulkin, J. and Myers, D. A. (2006) Long-term expression of corticotropin-releasing factor $(\mathrm{CRF})$ in the paraventricular nucleus of the hypothalamus in response to an acute colonic inflammation. Brain Research, 1071, 91-96. doi:10.1016/j.brainres.2005.11.071

[44] Sinniger, V., Porcher, C., Mouchet, P., Juhem, A. and Bonaz, B. (2004) C-fos and CRF receptor gene transcription in the brain of acetic acid-induced somatovisceral pain in rats. Pain, 110, 738-750. doi:10.1016/j.pain.2004.05.014

[45] Ulrich-Lai, Y.M., Xie, W., Meij, J.T.A., Dolgas, C.M., $\mathrm{Yu}$, L. and Herman, J. P. (2006) Limbic and HPA axis function in the animal model of chronic neuropathic pain. Physiology and Behavior, 88, 67-76. doi:10.1016/j.physbeh.2006.03.012

[46] Martinez, V., Wang, L., Million, M., Rivier, J. and Tache, Y. (2004) Urocortins and the regulation of gastrointesti- nal motor function and visceral pain. Peptides, 25, 17331744. doi:10.1016/j.peptides.2004.05.025

[47] Million, M., Grigoriadis, D. E., Sullivan, S., Crowe, P. D., Mcroberts, J. A., Zhou, H., Saunders, P. R., Maillot, C., Myer, E. A. and Tache, Y. A. (2003) Novel water-soluble selective CRF1 receptor antagonist, NBI 35965, blunts stress induced visceral hyperalgesia and colonic motor function in rats. Brain Research, 985, 32-42. doi:10.1016/S0006-8993(03)03027-0

[48] Million, M., Wang, L., Adelson, D.W., Yuan, P-Q., Maillot, C., Coutinho, S.V., Mcroberts, J.A., Bayati, A., Mattsson, H., Wu, V., Wei, J-Y, Rivier, J., Vale, W., Mayer, E.A. and Taché, Y. (2006) CRF2 receptor activation prevents colorectal distension induced visceral pain and spinal ERK1/2 phosphorylation in rats. Neurogastroenterology, 55, 172-181.

[49] Nijsen, M., Ongenae, N., Meulemans, A. and Coulie, B. (2005) Divergent role for CRF1 and CRF2 receptors in the modulation of visceral pain. Neurogastroenterology and Motilin, 17, 423-432. doi:10.1111/j.1365-2982.2005.00644.x

[50] Taché, Y. and Bonaz, B. (2007) Corticotropin-releasing factor receptors and stress-related alterations of gut motor function. Journal of Clinical Investigation, 117, 33-40. doi:10.1172/JCI30085

[51] Taché, Y., Martinez, V., Wang, L. and Million, M. (2004) CRF1 receptor signaling pathways are involved in stressrelated alterations of colonic function and viscerosensitivity: Implications for irritable bowel syndrome. British Journal Pharmacology, 141, 1321-1330. doi:10.1038/sj.bjp. 0705760 